\title{
Anion-Responsive Thiourea-based Gel Actuator
}

\author{
Seonggyun Ha, Juhyen Lee, Kyung-su Kim, Eun Jung Choi, Phannaro Nhem and Changsik \\ Song*
}

\section{Table of Contents}

Figure S1

Gelation time of the thiourea gel with differential diisothiocyanate monomers (TU1-6).

Figure S2

Conversion data of the TU1 gel in DMSO-d 6 solvent using ${ }^{1} \mathrm{H}$ NMR.

Figure S3

Storage modulus of the thiourea gel with differential diisothiocyanate monomers (TU1-6).

FT-IR spectrum of the 1,3,5-tris(4-aminophenyl) benzene (blue), 1,4-diphenylene diisothiocyanate (red), TU1 gel (black).

Figure S5

Gelation test of the TU0 depending on the concentration $(30 \sim 100 \mathrm{mM})$.

Figure S6

Porosity data of the (a)

(a) TU1 bulk gel and (b)

b) TU1 nanogel using BET measurement

(a) SEM image of the vacuum drying sample and (b) freezing drying sample of the TU1 gel.

Deprotonation of the TU0 depending on the anion series $\left(\mathrm{F}^{-}, \mathrm{CN}^{-}\right)$.

The recyclability test upon treating the thiourea gel bilayer film alternatively with $0.1 \mathrm{M} \mathrm{F}^{-}$solution, $\mathrm{MeOH}$ and DMSO (solvent) (1 cycle).

Figure S9

Figure S10

Figure S11

Figure S12
Thickness-dependent bending angles of thiourea gel bilayer films in a DMSO solution of $0.1 \mathrm{M} \mathrm{F}^{-}$at 45 seconds.

The ${ }^{1} \mathrm{H}$ NMR spectrum of TU0 (500 MHz, DMSO-d6).

The ${ }^{13} \mathrm{C}$ NMR spectrum of TU0 (125 MHz, DMSO-d 6 ). 


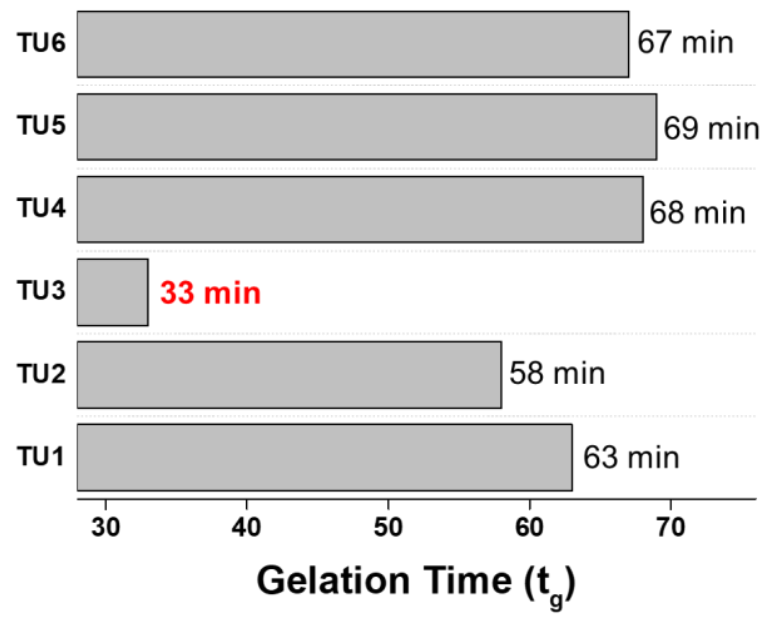

Figure S1. Gelation time of the thiourea gel with differential diisothiocyanate monomers (TU1-6).

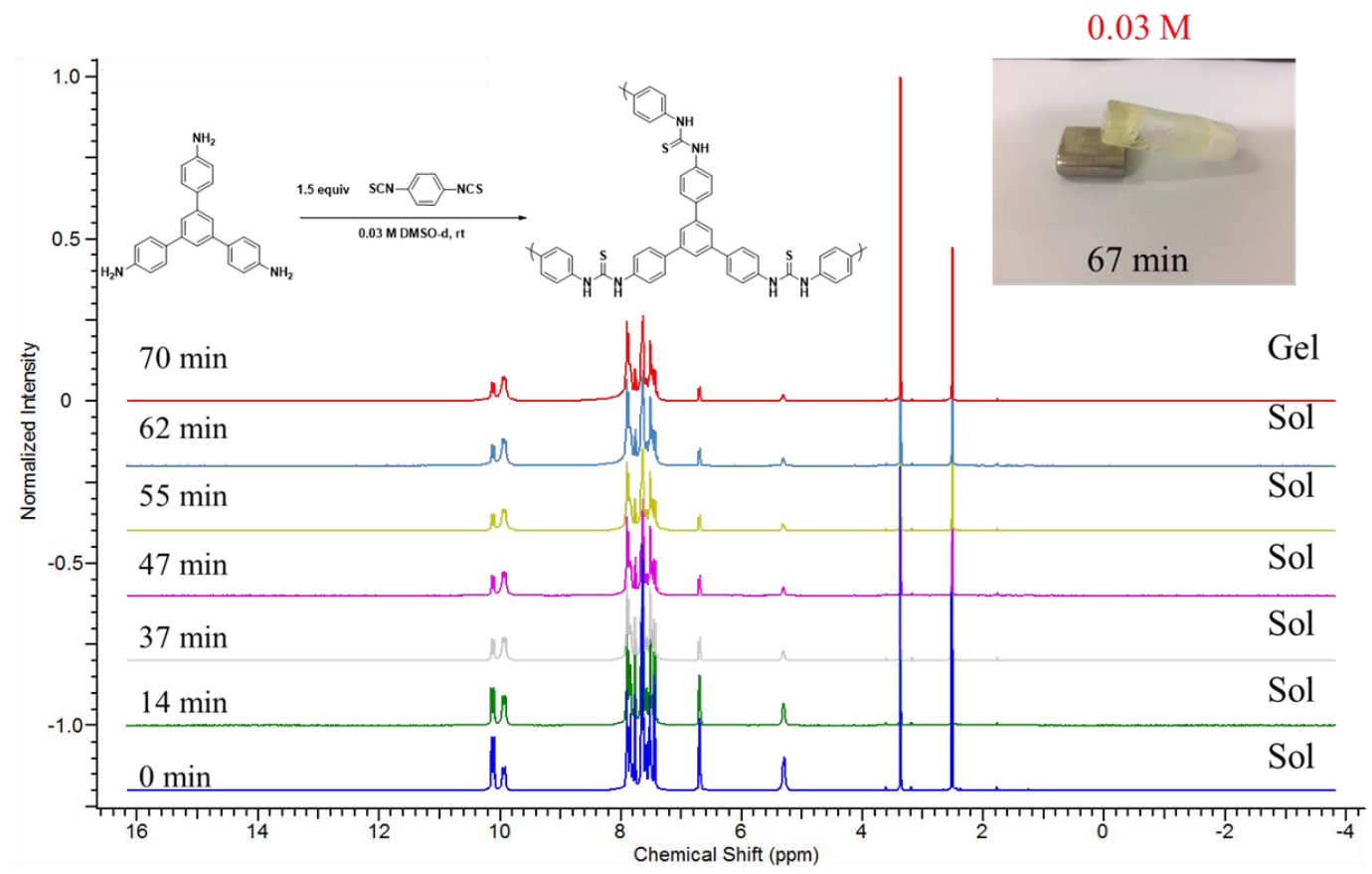

Figure S2. Conversion data of the TU1 gel in DMSO- $\mathrm{d}_{6}$ solvent using ${ }^{1} \mathrm{H}$ NMR. 


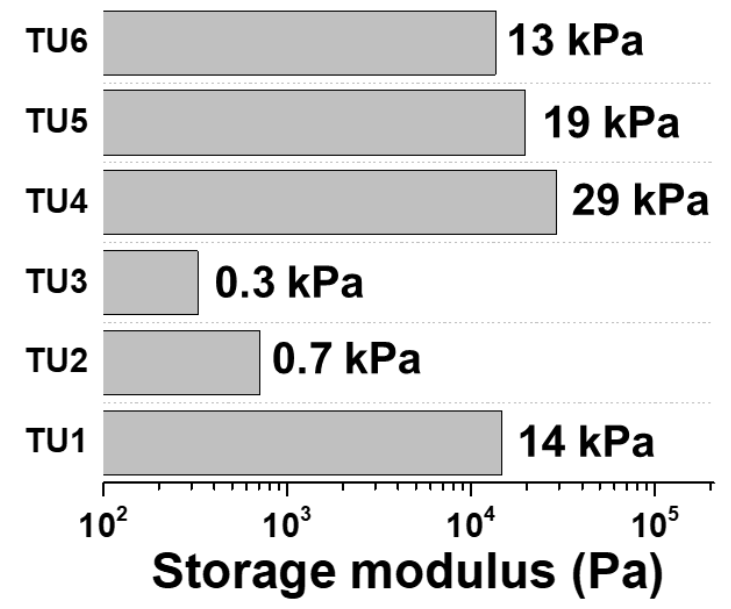

Figure S3. Storage modulus of the thiourea gel with differential diisothiocyanate monomers (TU1-6).

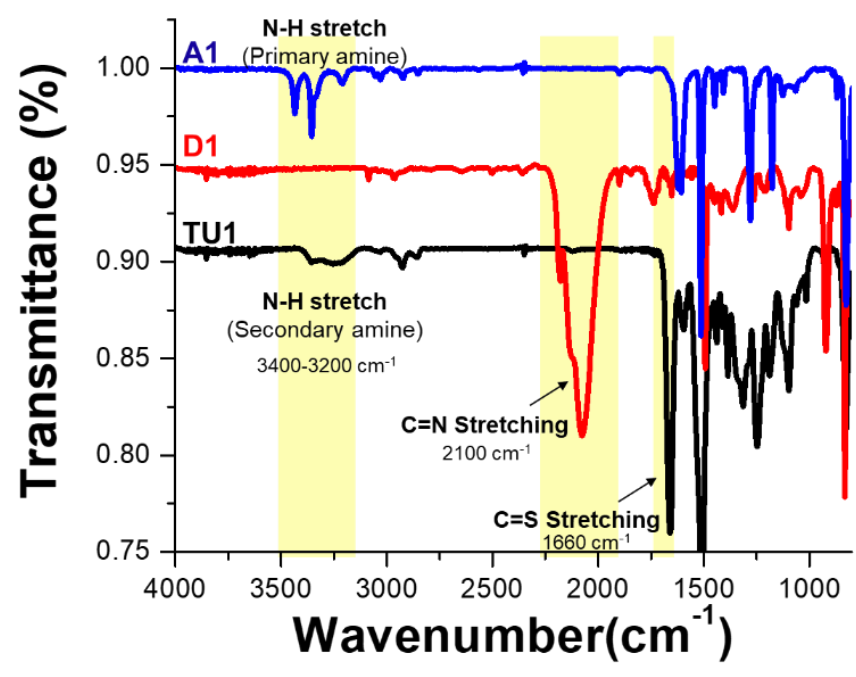

Figure S4. FT-IR spectrum of the 1,3,5-tris(4-aminophenyl) benzene (blue), 1,4-diphenylene diisothiocyanate (red), TU1 gel (black). 


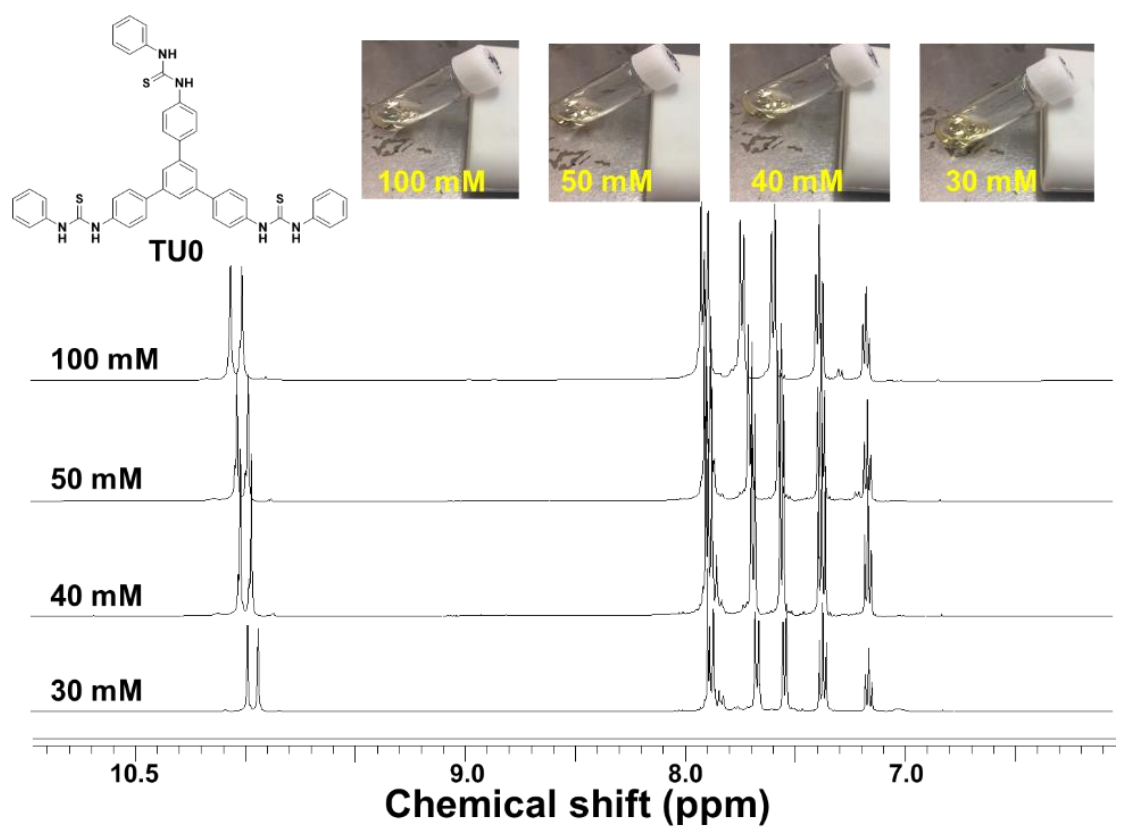

Figure S5. Gelation test of the TU0 depending on the concentration (30 100 mM).

(a)

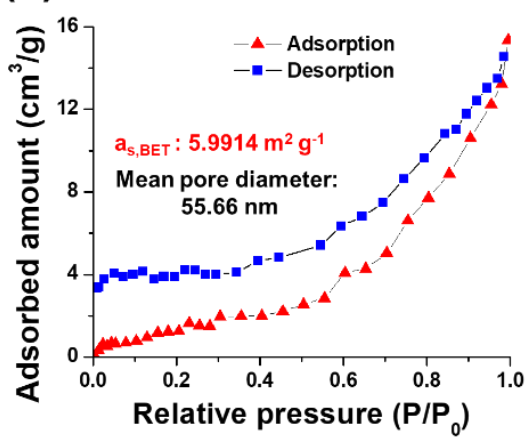

(b)

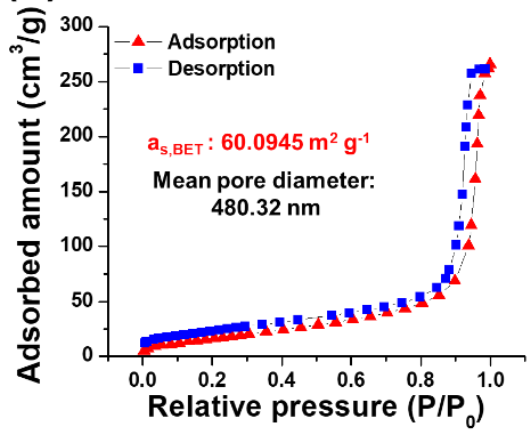

Figure S6. Porosity data of the (a) TU1 bulk gel and (b) TU1 nanogel using BET measurement. 

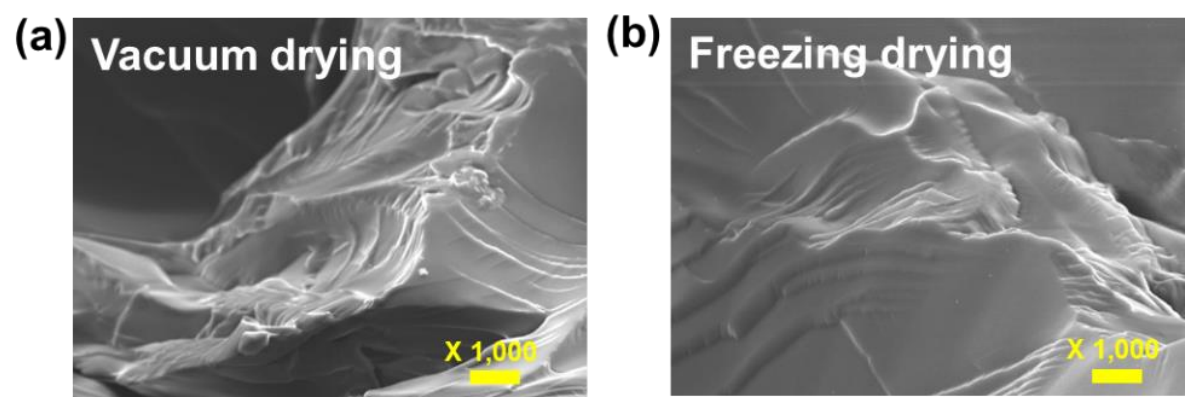

Figure S7. (a) SEM image of the vacuum drying sample and (b) freezing drying sample of the TU1 gel.

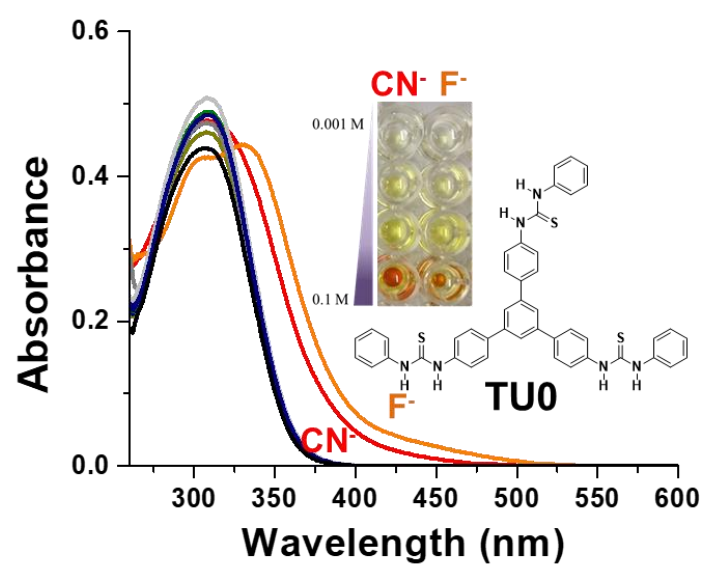

Figure S8. Deprotonation of the TU0 depending on the anion series $\left(\mathrm{F}^{-}, \mathrm{CN}^{-}\right)$. 


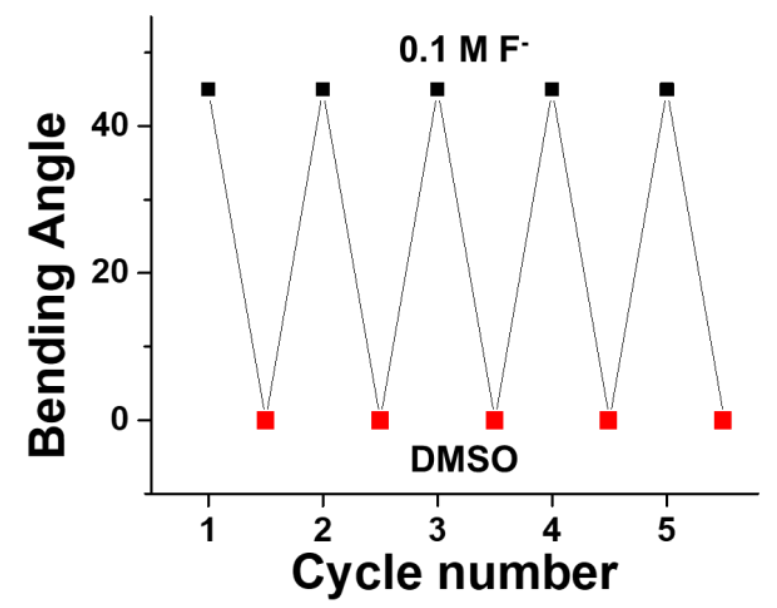

Figure S9. The recyclability test upon treating the thiourea gel bilayer film alternatively with $0.1 \mathrm{M}$ $\mathrm{F}^{-}$solution, $\mathrm{MeOH}$ and DMSO (solvent) (1 cycle).

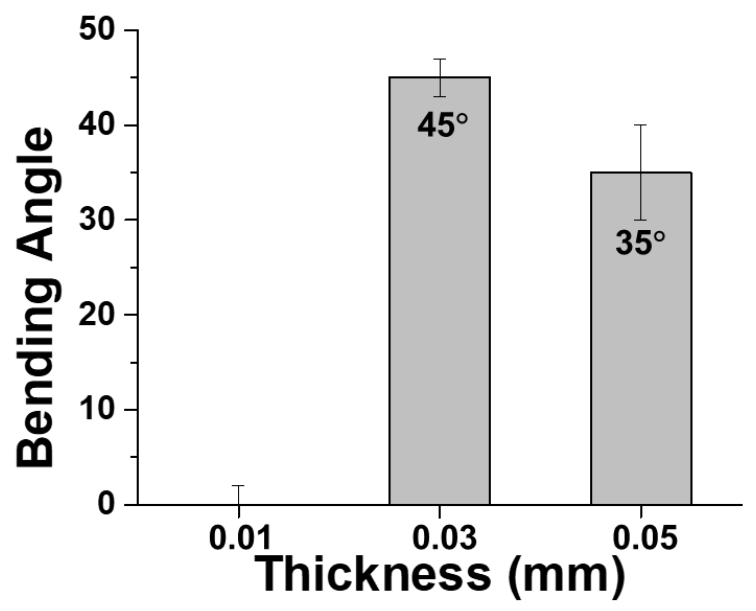

Figure S10. Thickness-dependent bending angles of thiourea gel bilayer films in a DMSO solution of $0.1 \mathrm{M} \mathrm{F}^{-}$at 45 seconds. 


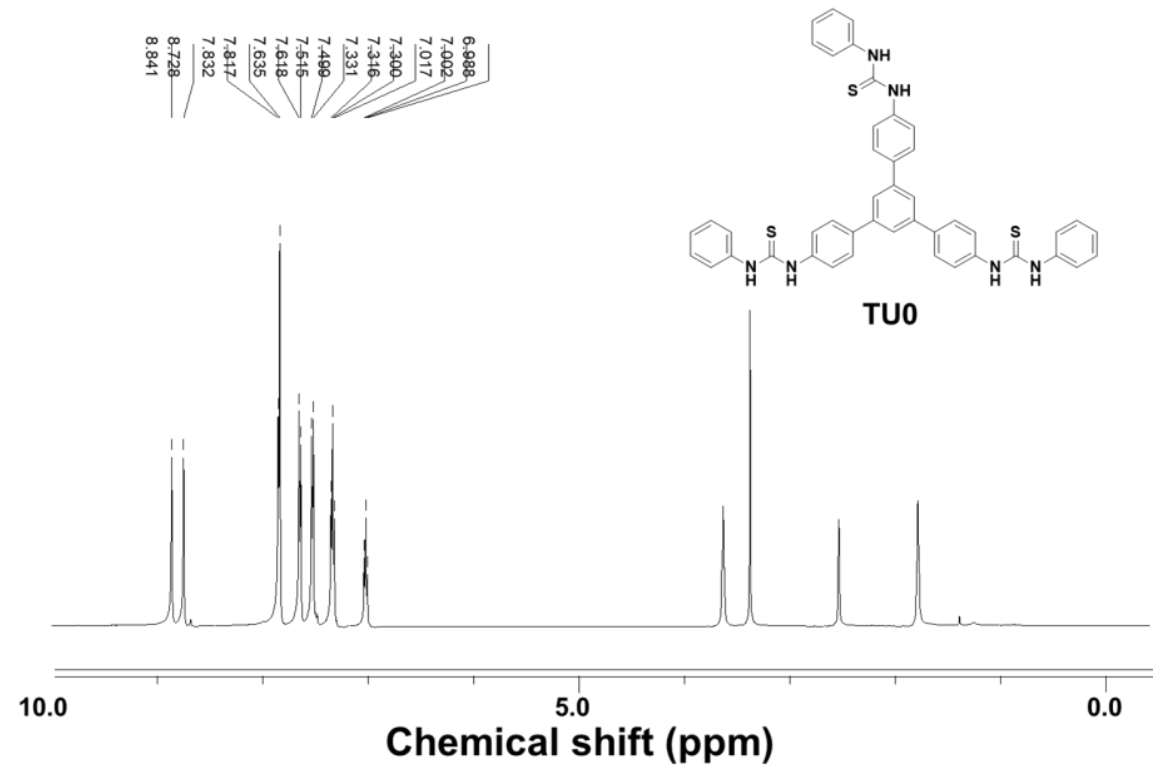

Figure S11. The ${ }^{1} \mathrm{H}$ NMR spectrum of TU0 (500 MHz, DMSO-d $\mathrm{d}_{6}$.

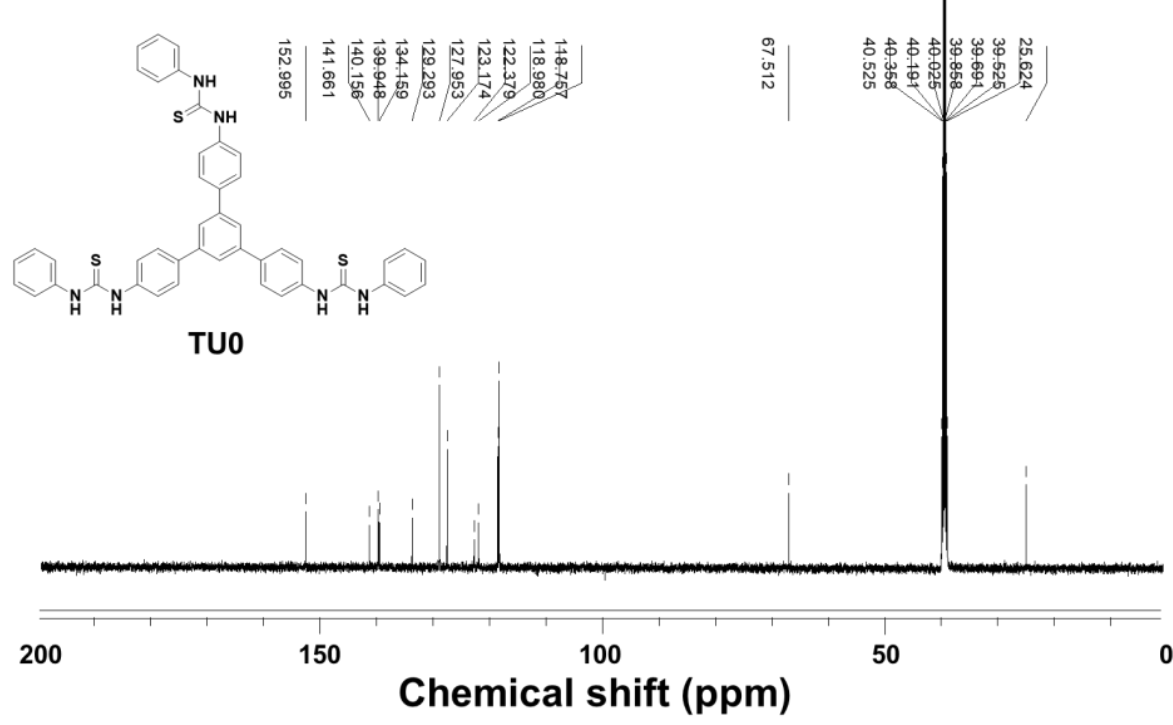

Figure S12. The ${ }^{13} \mathrm{C}$ NMR spectrum of TU0 (125 MHz, DMSO-d $\mathrm{d}_{6}$ ). 